\title{
Erratum to: Long-term outcome after sirolimus-eluting stents versus bare metal stents in patients with Diabetes mellitus: a patient-level meta-analysis of randomized trials
}

\author{
Antoinette de Waha - Alban Dibra - Sebastian Kufner • \\ Dietrich Baumgart - Manel Sabate - Aleardo Maresta • \\ Albert Schömig • Adnan Kastrati
}

Published online: 12 August 2011

(C) Springer-Verlag 2011

Erratum to: Clin Res Cardiol (2011) 100:561-570

DOI 10.1007/s00392-010-0278-8

The original version of this article unfortunately contains two mistyped values in Figs. $2 \mathrm{~b}$ and $5 \mathrm{a}$.

The correct figures are shown as follows:

The online version of the original article can be found under doi:10.1007/s00392-010-0278-8.

A. de Waha · A. Dibra . S. Kufner .

A. Schömig · A. Kastrati ( $\square)$

Deutsches Herzzentrum, Technische Universität,

Lazarettstr. 36, 80636 Munich, Germany

e-mail: kastrati@dhm.mhn.de

D. Baumgart

Preventicum-Klinik für Diagnostik, Essen, Germany

M. Sabate

Cardiovascular Institute, Hospital de la Santa Creu i Sant Pau,

Barcelona, Spain
A. Maresta
Division of Cardiology, Interventional Center,
S. Maria delle Croci Hospital, Ravenna, Italy 
Fig. 2

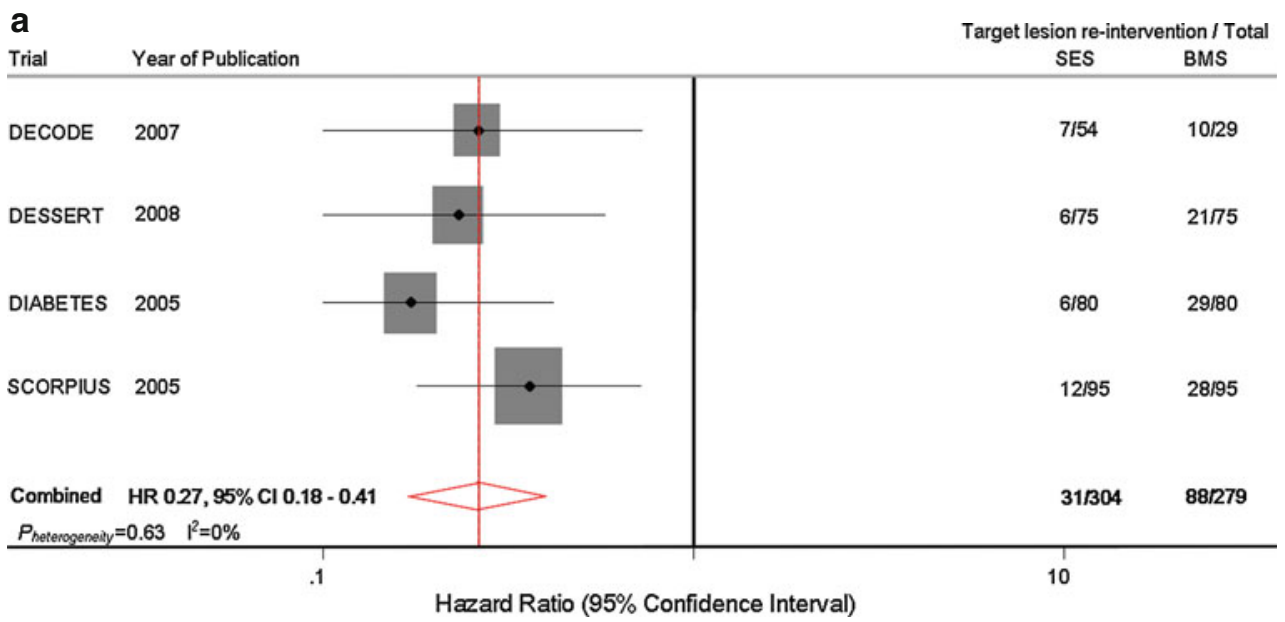

b

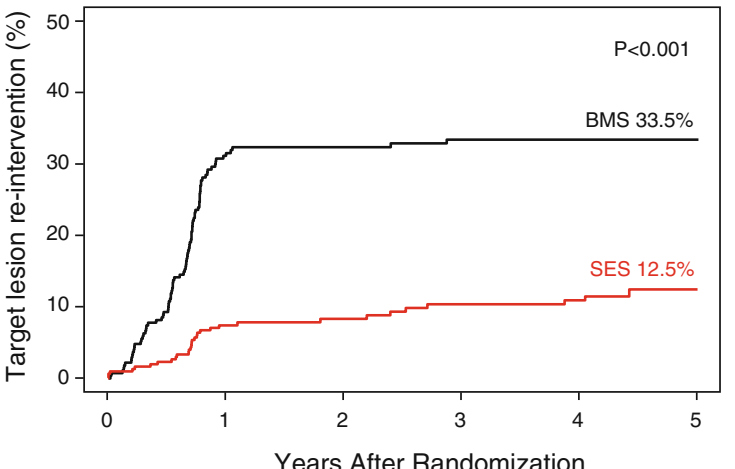

No. at Risk

Years After Randomization

$\begin{array}{lllllll}\text { Bare metal stents } & 279 & 173 & 139 & 126 & 111 & 49 \\ \text { Sirolimus-eluting } & & & & & & \end{array}$

stents

257

188

171

161

58 
Fig. 5

Trial Year of Publication

Stent Thrombosis / Total

SES BMS

DECODE 2007

DESSERT 2008

DIABETES 2005

SCORPIUS 2005

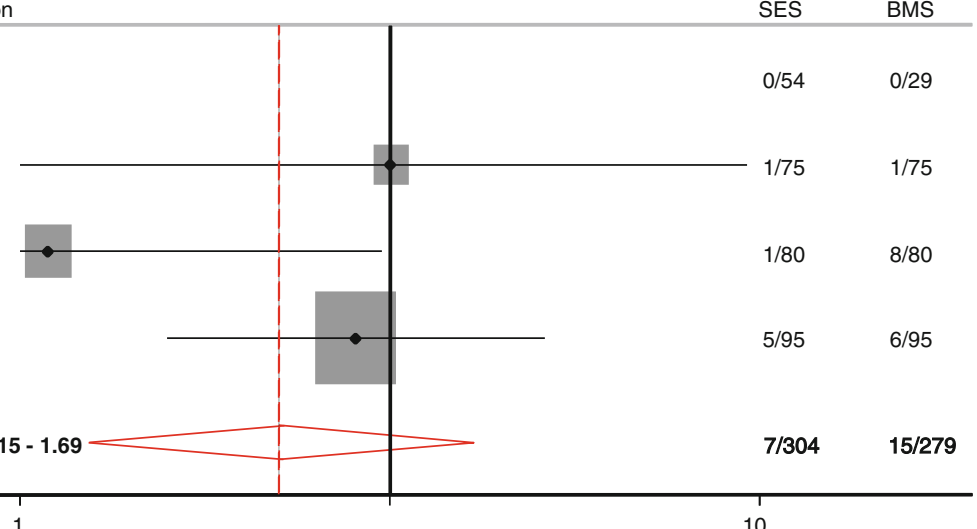

Hazard Ratio (95\% Confidence Interval)

b

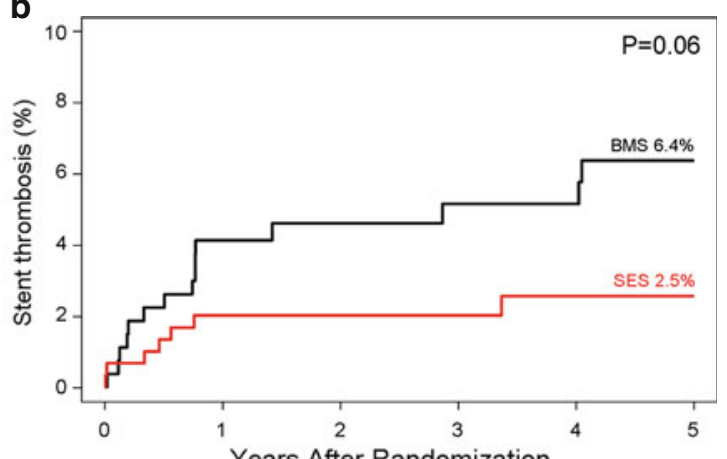

No. at Risk

Years After Randomization

$\begin{array}{lllllll}\text { Bare metal stents } & 279 & 240 & 191 & 174 & 155 & 64\end{array}$

Sirolimus-eluting

stents

304

273

198

184

173

64 